DOI 10.31558/2307-2318.2018.4.14

УДК 338.3

Коваш Лилия, доктор экономики, конференциар, Академия Экономических Знаний Молдовы, Кишинев

\title{
МОДЕЛЬ ДЛЯ ОПРЕДЕЛЕНИЯ УРОВНЯ УСТОЙЧИВОСТИ КОМПАНИИ
}

Целью данной статьи является описание модели оценки глобальных показателей экономических единиц, которая позволила бы им определить уровень устойчивости. Модель была использована в исследовании, направленном на оценку уровня устойчивости молдавских предприятий. Устойчивое развитие предлагает компаниям множество преимуществ, но это все еще предмет, с которым предприниматели в стране собираются познакомиться.

Эта статья является частью более широкого исследования, направленного на выявление влияния организационной культуры на устойчивое развитие организации. Методология, использованная при разработке статьи, в основном основана на количественном и качественном методе. Данные, полученные в результате расследования, были интерпретированы сравнительно и дедуктивно.

Ключевые слова: устойчивое развитие, стейкхолдеры, социальная ответственность, глобальная эффективность предприятия

\section{MODEL FOR DETERMINING THE COMPANY'S LEVEL OF STABILITY}

The purpose of this article is to describe a model for assessing the global performance of economic units that would allow them to determine their level of sustainability. The model was used in a study aimed at estimating the sustainability level of Moldovan enterprises. Sustainable development offers multiple advantage to companies, but it is still a subject with which entrepreneurs in the country are about to get acquainted.

This article is part of a broader study aimed at identifying the impact of organizational culture on the sustainable development of the organization. The methodology used in the development of the article is mainly based on a quantitative and qualitative method. The data obtained as a result of the investigation were interpreted in a comparative and deductive manner.

Key words: sustainable development, stakeholders, social responsibility, global enterprise efficiency

Изменения, происходящие в обществе, налагают на компании более жесткие требования к конкурентоспособности, чем в прошлом. Зависимость компании от ее стейкхолдеров (заинтересованных сторон) усиливается, а уровень ответственности перед потребителями, работниками, сообществом, окружающей средой и т. д. возрастает. В сложившихся условиях экономические единицы, заинтересованы в переосмыслении организации бизнеса и во внедрении новых подходов, учитывая принципы устойчивого развития.

Устойчивое развитие - это концепция, внедренная и распространенная в 1987 году Всемирной комиссией по окружающей среде и развитию (Комиссия Брундтланд), которая определяется как «Развитие сегодняшних потребностей без ущерба для способности будущих поколений удовлетворять свои собственные потребности». ${ }^{1}$

\footnotetext{
${ }^{1}$ www.geneva-international.org
} 
Устойчивое развитие компании невозможно, если деятельность фирмы не будет связана с интересами стейкхолдеров, не будет поддерживать диалог с ними, и не будет характеризоваться высоким уровнем прозрачности. Растет спрос на информацию о взаимоотношениях между компаниями, сотрудниками и сообществом. В то же время усиливается спрос на раскрытие информации о социальной и экологической практике компаний.

Развивая концепцию корпоративной социальной ответственности, стремления компаний обеспечить благоприятную внешнюю среду для устойчивого развития, увеличение затрат на бизнес создало предпосылки для возникновения большого числа инициатив, направленных на создание общей основы принципов и норм корпоративного поведения, стандартов разработки и аудита социальной отчетности.

Некоторые из них приобрели значительную ценность и поддерживаются ведущими международными компаниями, правительственными организациями и НПО, а другие используются только в некоторых странах или регионах.

Основные стандарты, используемые при подготовке социальных отчетов: Глобальный договор; GRI (Глобальная инициатива по отчетности); AA1000 (Институт социальной и этической отчетности); SA 8000 (социальная отчетность 8000); Стандарт ISO 26000 и т. д.

По мнению Миронюк (2009), анализ устойчивого предприятия должен учитывать, что философия социальной ответственности не противоречит концепции эффективности, поскольку она не предлагает исключить прибыль из уравнения динамики экономики и общества. Вклад предприятия в устойчивое развитие заключается не в том, что делает ответственное предприятие с $1 \%$ своей прибыли, а в том, как он получает $99 \%$ этой прибыли. ${ }^{2}$

В специализированной литературе существует ряд попыток разработать модель общей оценки эффективности деятельности предприятия с целью определения уровня устойчивости компании.

Обзор исследований по оценке устойчивости компании был проведен Ganescu (2012). ${ }^{3}$ Автор анализирует специализированную литературу, идентифицирует показатели, а также этапы процесса измерения устойчивости экономической единицы. Заслуживает внимания модель LCSP, предложенную Velevoй и Ellenbecker (2001), которая позволяет промышленным компаниям своевременно определять и контролировать свои действия для устойчивой деятельности. ${ }^{4}$

Использование этих моделей ориентировано на определение уровня устойчивости крупных предприятий, особенно для компаний, зарегистрированных на Фондовой бирже. В этом случае компании заинтересованы рассчитывать ряд показателей используемых в данных моделей.

Но большинство малых и средних предприятий не вычисляют соответствующие показатели, что усложняет процесс оценки глобальных показателей по существующим

\footnotetext{
${ }^{2}$ Marilena Mironiuc, Analiza financiară versus analiza extra-financiară în măsurarea performanțelor întreprinderii durabile, Simpozion științific, Analiza economico-financiară și evaluarea proprietăților, ASE, București, 29-31 Mai 2009.

${ }^{3}$ Mariana Cristina Ganescu, Responsabilitatea soaială a întreprinderii ca strategie de creare și consolidare a unor afaceri sustenabile, Economie teoretică și aplicată, Volumul XIX(212), Nr. 11 (576), p. 93-109, 2012.

${ }^{4}$ Veleva V., Ellenbecker M., Indicators of sustenaible production: framework and methodology. Elsevier. Journal of Clean Production, v.10, p. 520-549, 2001.
} 
моделям. Таким образом, необходимо разработать жизнеспособную, удобную в использовании модель для малых и средних компаний.

При проведении исследования, главная цель которого - оценить уровень устойчивости компаний Республики Молдова, была разработана собственная модель для расчета глобальной эффективности экономической единицы, охватывающая экономические, социальные и экологические показатели.

Для проведения сравнительного анализа результатов, полученных компаниями Республики Молдова, была предложена классификация предприятий в 5 уровнях, в соответствии с которыми оценивается устойчивое развитие.

Определение собственных показателей компании было проведено путем опроса, посредством структурированного интервью, а также финансовых отчетов компаний за 2016 и 2017 годы. Опрос был проведен в офисах компаний в течение нескольких месяцев, с января по апрель 2018. В интервью приняли участие представители руководства предприятий.

Опрос проводился на 28 молдавских предприятиях. Основным критерием выбора компаний была их принадлежность к различным областям деятельности, а также и разнообразие размеров предприятий. Это разнообразие, необходимо исходя из специфики исследования, так как важно проанализировать применимость модели в различных секторах деятельности и определить соответствие между предлагаемыми показателями и достигнутыми результатами деятельности компании.

Таким образом, $46 \%$ от общего числа предприятий представляют крупные компании, а доля малых и средних предприятий составляет - 54\%. Анализируемые компании относятся к 10 отраслям деятельности, причем большинство компаний занимаются производством, оптовой и розничной торговлей, транспортировкой и хранением, гостиничным и ресторанным бизнесом.

Bce данные были внесены в программу статистического анализа SPSS. Для применения модели были рассмотрены основные области оценки предприятия: экономическая, социальная и экологическая. В каждой области были определены конкретные критерии, имеющие определенный вес в пределах заданного максимального балла и с учетом коэффициента важности, соответствующего каждому критерию.

Принимая во внимание специфику и условия экономики Республики Молдова, для определения экономической эффективности предприятия, мы использовали набор из шести показателей, которые оценивались по пяти бальной шкале (Таблица 1).

Таблица 1. Доля показателей эффективности при расчете глобальной эффективности предприятия

\begin{tabular}{|l|c|}
\hline \multicolumn{1}{|c|}{ Показатели } & Коэффициент важности \\
\hline 1. Экономический аспект & \\
1.1 Текущая ликвидность & $8,33 \%$ \\
1.2 Платежеспособность & $8,33 \%$ \\
1.3 Финансовая стабильность & $8,33 \%$ \\
1.4 Экономическая рентабельность & $8,33 \%$ \\
1.5. Финансовая рентабельность & $8,33 \%$ \\
1.6. Ротация оборотных средств & $8,33 \%$ \\
\hline 2. Социальный аспект & $5 \%$ \\
2.1. Деятельность, ориентированная на сотрудников & $5 \%$ \\
2.2 Безопасность и охрана труда & $5 \%$ \\
2.3 Защита потребителей & $5 \%$ \\
2.4 Адаптация к изменениям в сообществе & \\
\hline
\end{tabular}




\begin{tabular}{|c|c|}
\hline $\begin{array}{l}2.5 \text { Мероприятия, направленные на развитие } \\
\text { сообществ }\end{array}$ & $5 \%$ \\
\hline 3. Экологический аспект & \\
\hline 3.1 Эффективное использование ресурсов & $5 \%$ \\
\hline 3.2 Сокращение отходов и загрязнений & $5 \%$ \\
\hline 3.3 Утилизация отходов & $5 \%$ \\
\hline $\begin{array}{l}\text { 3.4. Забота об окружающей среде при } \\
\text { проектировании производственных процессов }\end{array}$ & $5 \%$ \\
\hline $\begin{array}{l}3.5 \text { Добровольные меры, направленные на защиту } \\
\text { окружающей среды в сообществе }\end{array}$ & $5 \%$ \\
\hline
\end{tabular}

\section{Источник: Разработано автором}

Учитывая, что действия в социальной области в значительной степени являются добровольными и могут быть разнообразными, социальные показатели были структурированы на пять видов обязанностей по отношению к основным стейкхолдерам компании. В попытке структурировать эту обширную область были выбраны те стейкхолдеры, с которыми взаимодействует большинство компаний, независимо от их сферы деятельности: сотрудники, потребители, сообщество.

В рамках каждого вида обязанностей были выделены пять видов действий, которые чаще выполняются компаниями, но позволяя респондентам, при необходимости, добавить своё собственные предложение.

Определение социальных показателей компании было сделано путем расчета количества социальных инициатив, сделанных экономической единицей за определенный период времени, и присвоения определенной категории социальной эффективности (Таблица 2).

Таблица 2. Интерпретация классификации по категориям социальных показателей

\begin{tabular}{|c|c|l|}
\hline $\begin{array}{c}\text { Категории } \\
\text { эффективности }\end{array}$ & Всего баллов & Уровень социальной эффективности \\
\hline $\mathbf{5}$ & $\mathbf{2 1 - 2 5}$ & Очень хороший \\
\hline $\mathbf{4}$ & $\mathbf{1 6 - 2 0}$ & Хороший \\
\hline $\mathbf{3}$ & $\mathbf{1 1 - 1 5}$ & Умеренный уровень \\
\hline $\mathbf{2}$ & $\mathbf{6 - 1 0}$ & Минимальное участие \\
\hline $\mathbf{1}$ & $\mathbf{0 - 5}$ & $\begin{array}{l}\text { Полное отсутствие социальной } \\
\text { вовлеченности }\end{array}$ \\
\hline
\end{tabular}

Источник: Разработано автором

После анализа социальных показателей компании было установлено, что компании предпочитают более активно участвовать в мероприятиях, ориентированных на сотрудников - 33,1\%, после чего адаптация к изменениям в сообществе - $23,3 \%$, и охрана труда - $18,8 \%$ (рис. 1 ).

Очень небольшой процент компаний отметил, что они осуществляют социальную деятельность, ориентированную на развитие сообщества - 13,7\%, а меньшая доля инициативы, направленные на защиту потребителей - 11,0\%. 


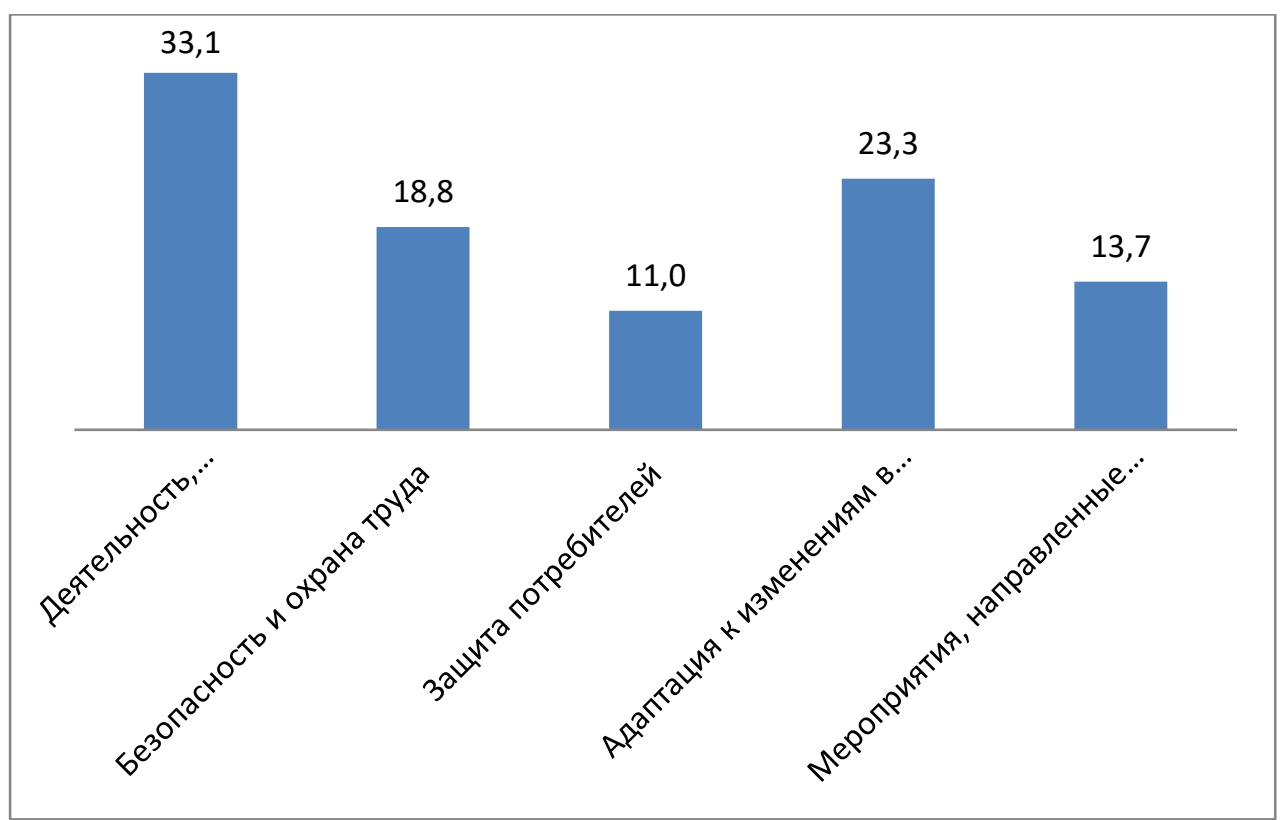

Рисунок 1. Доля социальных действий, предпринятых компаниями респондентами

Источник: Разработано автором

Из общего числа социальных действий, предпринятых обследованными компаниями, почти все предприятия считают необходимым обеспечить равные возможности и баланс между работой и жизнью. Многие из них прилагают определенные усилия для улучшения условий труда и для обучения и развития персонала.

Однако очень небольшое число компаний вовлечено в услуги, ориентированные на клиента, по отношению к людям с ограниченными возможностями, профилактику профессиональных заболеваний и т.д. Предприятия рассматривают их как дополнительные затраты, не принимая во внимание, что эти инициативы могут оказать положительное влияние на экономические показатели, постепенно меняя восприятие сотрудников, потребителей и сообщества в отношении компании как справедливой и ответственной организации.

Экологические показатели в предлагаемой модели также были структурированы на пять видов корпоративной ответственности в отношении охраны окружающей среды. В свою очередь, каждый вид ответственности состоял из пяти действий, которые возможно предпринять в данной области. Исходя из того, что компании могут добровольно осуществлять неограниченное количество действий по собственной инициативе, организация по своему усмотрению могла дополнить ряд этих действий.

Определение экологических показателей осуществляется так же, как и социальные, путем расчета количества инициатив, предпринятых компанией в течение определенного периода времени и приписыванием определенной категории экологических показателей.

Данные, собранные в ходе исследования, показывают, что компании запускают ряд экологических действий, выходящих за рамки юридических требований. Из пяти видов природоохранных обязанностей, предложенных респондентам, проявились некоторые тенденции в данном направлении. 


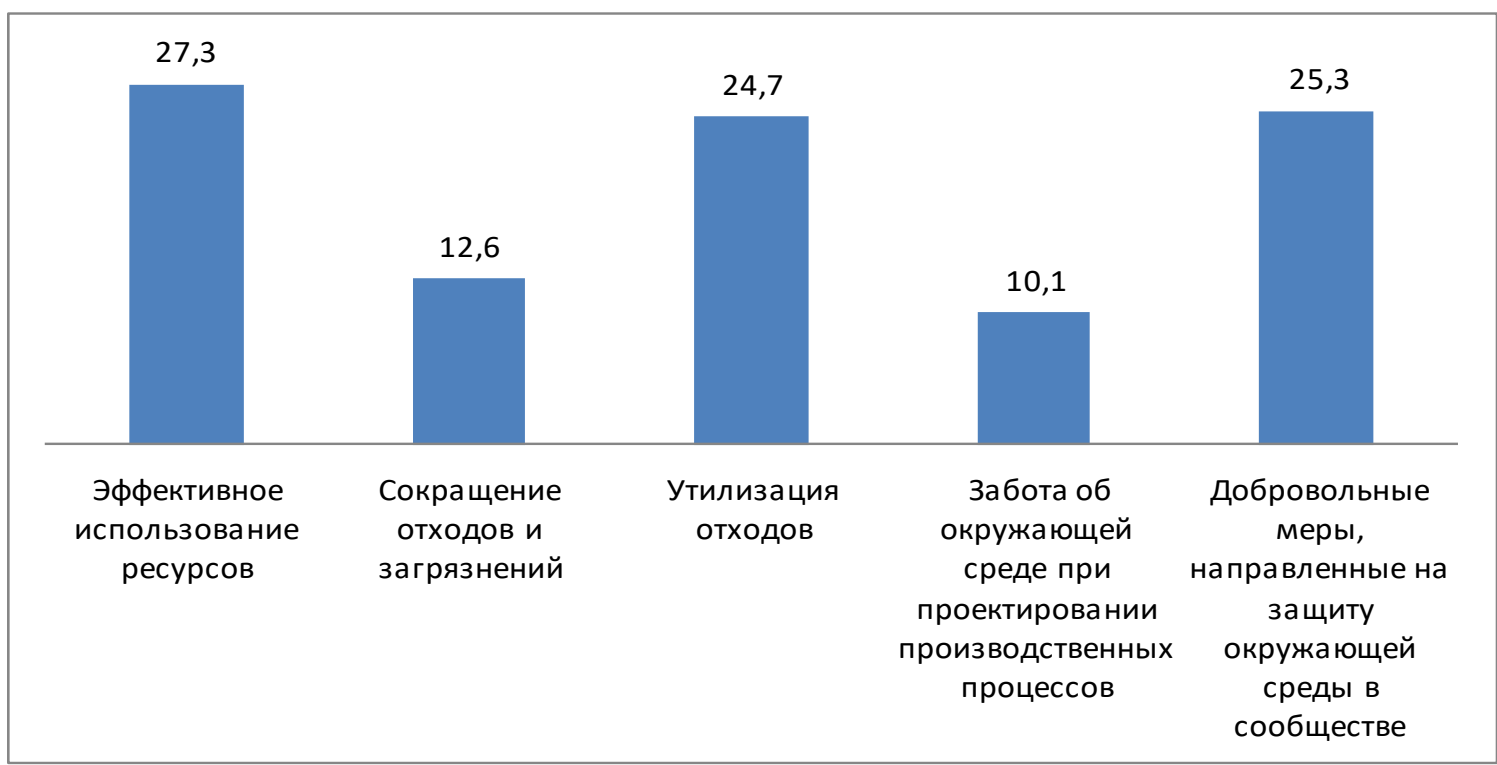

Рисунок 2. Доля экологических действий, предпринятых компаниями респондентами Источник: Разработано автором

Экономические единицы предоставили самую высокую долю - 27,3\% эффективному использованию ресурсов. Мы считаем, что этот момент вызван экономическими интересами. Отрадно, что 25,3\% составляют добровольные действия, направленные на защиту окружающей среды в обществе. Большое количество компаний предпринимают усилия по утилизации отходов - 24,7\% (рисунок 2). Но наблюдается мало инициатив компаний по сокращению отходов и загрязнений - 12,6\%, а также инициатив по анализу экологических проблем на этапах проектирования производственных процессов или продуктов - 10,1\%.

Результаты опроса показывают, что молдавские компании уделяют меньше внимания экологическим аспектам по сравнению с социальными проблемами. Среди более частых действий: посадка зеленых зон, эффективное использование сырья. Очень небольшое число компаний предпринимают инициативы по информированию деловых партнеров по вопросам окружающей среды, проведению экологических оценок поставщиков и т. д. Эти мероприятия, не требуют значительных финансовых ресурсов, но могут оказать благотворное влияние на имидж компаний и соответственно, на экономические показатели предприятий.

После определения экономических, социальных и экологических показателей, был произведен расчет глобальной эффективности предприятия и определен соответствующий уровень устойчивого развития. В зависимости от результата, компании присваивается определенный уровень устойчивости, от 1 до 5 (Таблица 3).

Таблица 3. Уровни устойчивого развития

\begin{tabular}{|c|c|}
\hline Глобальная эффективность предприятия & Уровень устойчивого развития \\
\hline $1.00-2.00$ & $\mathbf{G 1}$ \\
\hline $2.00-3.00$ & $\mathbf{G 2}$ \\
\hline $3.00-4.00$ & $\mathbf{G 3}$ \\
\hline $4.00-4,50$ & $\mathbf{G 4}$ \\
\hline $4,50-5.00$ & $\mathbf{G 5}$ \\
\hline
\end{tabular}

Источник: Разработано автором 
Каждая категория эффективности предприятия, рассчитанная с использованием рассматриваемой модели, описывает определенное устойчивое поведение:

G1 - Очень плохое финансовое состояние и практически отсутствие социальных и экологических действий;

G2 - характеризует приемлемую, но нестабильную экономическую ситуацию со спорадическими социальными и экологическими инициативами;

G3 - характерно для компании с более стабильной финансовой ситуацией и более ответственной в своих отношениях с заинтересованными сторонами, реализуя определенные запланированные инициативы;

G4 - характерно для субъекта с хорошей экономической ситуацией, социальные и экологические действия становятся активными, осуществляются на уровне стратегического управления;

G5 - характеризует превосходный уровень устойчивого поведения при активном участии во всех областях.

Анализ общей эффективности, включающей экономические, социальные и экологические показатели предприятий, участвующих в опросе, позволил изложить текущую ситуацию устойчивого развития молдавских компаний (рисунок 3 ).

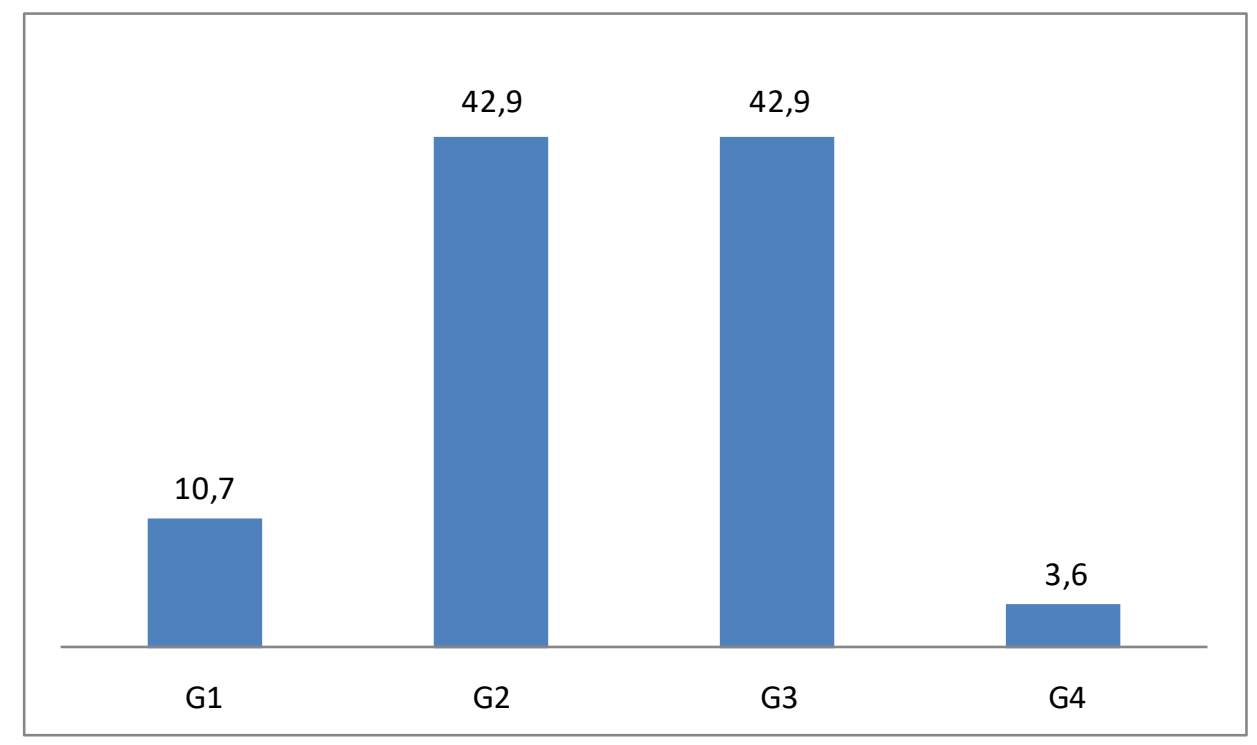

Рисунок 3. Уровень устойчивости, продемонстрированный анализируемыми компаниями

Источник: Разработано автором

Результаты исследования на предприятиях Республики Молдова показывают, что есть предприятия - 10,7\% из общего количества, которые характеризуется самым низким уровнем устойчивости. В их случае неблагоприятная экономическая ситуация сосуществует с отсутствием действий, направленных на общество и окружающую среду.

Равное количество экономических единиц, 42,9\%, относится ко второй и третьей степени устойчивости. Это свидетельствует о том, что отечественные компании начинают более позитивно относиться к устойчивому развитию, но эти действия не рассматриваются на должном уровне, и не интегрируются в организационные стратегии. 


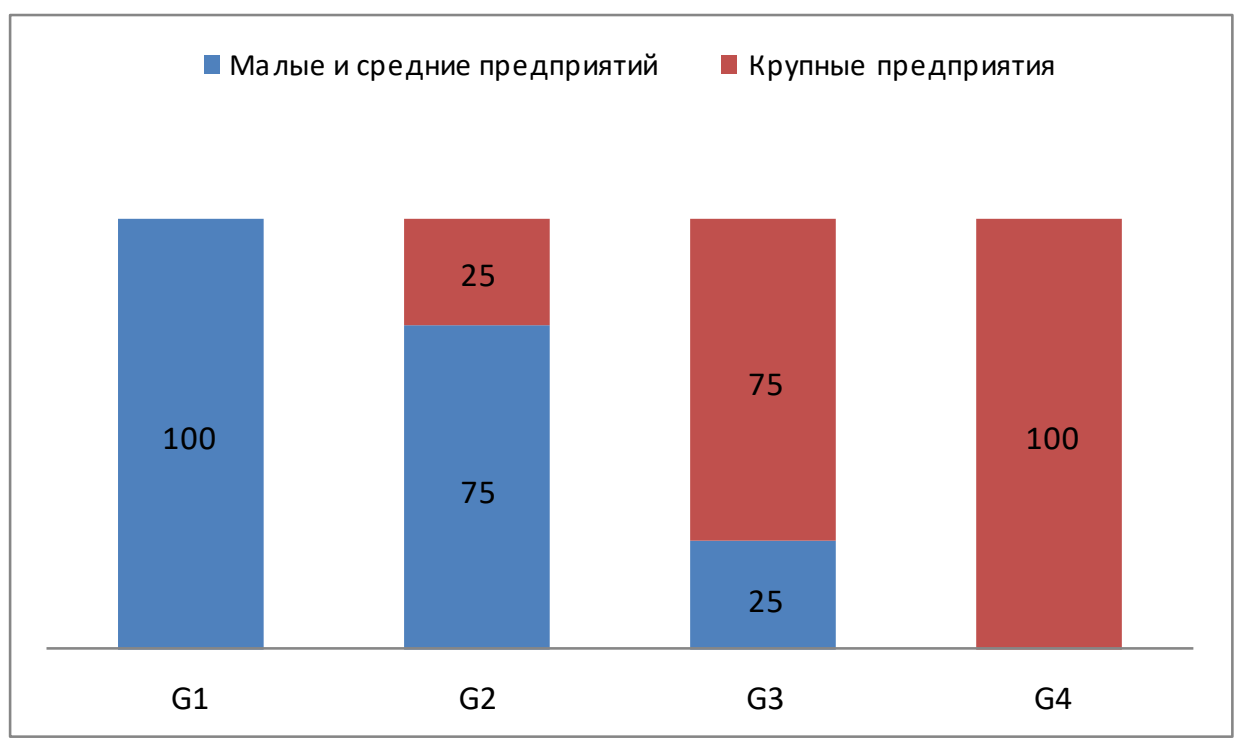

Рисунок 4. Доля крупных, малых и средних предприятий по уровню устойчивости Источник: Разработано автором

Только 3,6\% опрошенных компаний набрало количество баллов, позволяющее им относиться к четвёртому уровню устойчивости. Ни одна из включенных в опрос компаний, не накопила требуемого показателя для высшего уровня устойчивости.

Особый интерес представляет анализ уровня устойчивости с учетом размеров компаний (рисунок 4). В исследовании подчеркивается, что доля малых и средних предприятий уменьшается по мере увеличения уровня устойчивости, а для крупных предприятий ситуация меняется на противоположную. На IV-м уровне устойчивости $100 \%$ компаний являются большими, на III-м уровне - $75 \%$, на II -м уровне - $25 \%$, а на первом уровне нет ни одного крупного предприятия.

Таким образом, использование модели оценки устойчивости бизнеса может дать нам много практических преимуществ, а именно: сравнительный анализ глобальной эффективности деятельности компании; определение рейтинга компании по уровню устойчивости; а также выявление сильных и слабых сторон компаний для устойчивого развития. Оценка уровня устойчивости компании служит важным информационным ресурсом, который позволяет оптимизировать процесс стратегического планирования и другие аспекты управления организацией, улучшая взаимоотношения со стейкхолдерами. 